\title{
REMOVAL OF Pb(II) FROM WASTEWATER USING CITRUS LEMON BARK
}

\author{
A. B. Sahare, K. N. Puri \\ Asst. Professor, Shri Shivaji College of Arts, Commerce \& Science, Akola. \\ E-mail: atul_institute@yahoo.com, Contact No.: 9423410943
}

\begin{abstract}
:
Dried, powdered and chemically treated tree bark of Citrus limon has been used for the removal of $\mathrm{Pb}(\mathrm{II})$ metal ions from wastewater. The adsorption process was studied as a function of $\mathrm{pH}(2-9)$, contact time (0-120min), initial concentration (20$55 \mathrm{mg} / \mathrm{L})$, doses of bark $(0.5-3 \mathrm{~g}) \&$ temperature $\left(32-90^{\circ} \mathrm{C}\right)$. It was observed that the $\mathrm{pH}$ has marked effect on $\mathrm{Pb}(\mathrm{II})$ uptake. Batch study shows that about $82 \%$ removal of $\mathrm{Pb}(\mathrm{II})$ takes place over the $\mathrm{pH}$ range of $6-7$ and contact time of 1.5 hour at initial concentration of $20 \mathrm{mg} / \mathrm{L}$. The adsorption of $\mathrm{Pb}(\mathrm{II})$ is inversely related to the temperature. The results obtained in batch experiments were compared with that of Granular Activated Charcoal (GAC). The bark was found to be efficient media for removal of $\mathrm{Pb}(\mathrm{II})$ as compared to $\mathrm{GAC}$ in continuous mode. The column having $2 \mathrm{~cm}$ diameter with bed depth of $30 \mathrm{~cm}$ was used for the treatment of water containing $\mathrm{Pb}(\mathrm{II})$ separately at concentration $20 \mathrm{mg} / \mathrm{L}$ and flow rate $9.5 \mathrm{ml} / \mathrm{min}$. The column parameter

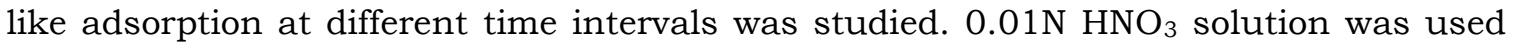
for desorption of adsorption column and column regenerated using distilled water.
\end{abstract}

\section{Introduction:}

Since start of industrialization in nineteenth century, the pollution increased considerably. Many industries particularly in the trade of metal processing operations represent significant sources of toxic metal emission. Metal contamination has become global problem. The main reason of the metal contamination is that most of the land is irrigated by waste water generated from industries. The waste water commonly includes $\mathrm{Cd}, \mathrm{Pb}, \mathrm{Cu}, \mathrm{Ni}$ and $\mathrm{Co}$. The heavy metals are not biodegradable and their presence in streams and lakes leads to bio accumulation in living organisms causing health problems in animals, plants and human beings. 
The $\mathrm{Pb}(\mathrm{II})$ have been selected on the basis of availability of wastewater containing these two metals. Again these are also known to be highly toxic and responsible for various diseases to human being. The $\mathrm{Pb}(\mathrm{II})$ is well known responsible for extinction of Roman Empire. Here we have make an attempt to remove these two metal ions from wastewater using naturally occurring polymeric material after some treatment which is very cheap as compared to GAC. The experiments have been done totally on laboratory scale not in pilot plant. Therefore, there are some degree of variation are possible in result of the experiments. But, still such attempts are necessary for the benefit of society.

\section{Experimental Details:}

The metal ions adsorption studies were performed in two phases Batch Study and Column Study. The batch study was carried out to fix the necessary conditions for adsorption of metal ions. Hence, all the experiments performed by using synthetically prepared solutions in batch study. While in case of Column Study the collected samples of wastewater have been used.

1) Collection of waste water samples: The waste water samples were collected from the Industrial Area of Nagpur. The collected samples were tested for $\mathrm{Pb}(\mathrm{II})$ ion content on trial and error basis.

2) Batch Study: In batch study the conditions for adsorption have been fixed such as $\mathrm{pH}$, contact time, etc. using synthetically prepared solutions. The batch study carried out by conducting various experiments using treated bark of Citrus limon and GAC. The bark power was treated using formalin solution and $0.1 \mathrm{~N}$ nitric acid for three day, and then sun dried. The metal ion concentration of the solution was analyzed before and after adsorption using standard methods. The experimental parameters studied by using bark and GAC includes - 

a) Effect of $\mathrm{pH}$
b) Effect of contact time
c) Effect of initial metal ion concentration.
d) Effect of dosages
e) Effect of temperature

3) Column Study: The Column Study was carried out using a fixed column of treated Citrus limon bark having $2 \mathrm{~cm}$ diameter and $30 \mathrm{~cm}$ bed depth. The two ends plugged with glass wool. Similar column was prepared using GAC. The optimum condition for adsorption was maintained on collected wastewater samples such as $\mathrm{pH}$. The wastewater sample having optimum $\mathrm{pH}$ and known concentration of metal ion was then passed through the column using peristaltic pump in back flow mode. The rate of flow of solution was maintained at $9.5 \mathrm{ml}$ per minute. The effluent collected was analyzed for metal ion content at different time intervals using standard methods. The results obtained are compared with the results obtained by using packed column of GAC.

The column can be regenerated by using $0.01 \mathrm{~N}$ nitric acid and reused. The experiments have been performed several times to find the relevant data.

\section{Result and Discussion:}

The result and discussion are done under two head Batch study and column study. As mentioned earlier that synthetically prepared wastewater has been used only for batch study. The concentrations of $\mathrm{Pb}(\mathrm{II})$ was selected to be $20 \mathrm{mg} / \mathrm{L}$ each.

\section{A] Batch Study:}

1) Effect of pH: $\mathrm{pH}$ is an important parameter for adsorption of metal ions because it affects the solubility of the metal ions. In this study $1 \mathrm{gm}$ each of treated tree bark and GAC was agitated with $100 \mathrm{ml}$ metal ion 
solutions at different $\mathrm{pH}$ at $32^{\circ} \mathrm{C}$ for 1.5 hour and analyzed for metal content.

It has been found that the adsorption of metal ions gradually varies as the initial $\mathrm{pH}$ of the solution is raised from 2 to 9 . The maximum adsorption of $\mathrm{Pb}(\mathrm{II})$ observed at $\mathrm{pH}$. The final $\mathrm{pH}$ has been found to be less than initial $\mathrm{pH}$ of solution for tree bark while the $\mathrm{pH}$ of the solution increases for GAC. The maximum removal of $\mathrm{Pb}(\mathrm{II})$ ion from the solution on tree bark is found to be $82.75 \%$ and on GAC was found to be $80.95 \%$. Hence, $\mathrm{pH}$ of the solution was maintained at 7 for further investigation. The results are shown in Fig. 1.

2) Effect of Contact Time: In this study $100 \mathrm{ml}$ metal ion solution was agitated with $1 \mathrm{~g}$ each treated tree bark \& GAC separately for different time intervals. It is evident from the study that about $40 \%$ removal of metal ions takes place within 15 minutes. It indicates that the adsorption of metal ions is very fast. The concentration of metal ions in solution remains fairly constant after a contact time of $1 \mathrm{hr}$. Therefore, the contact time of $1.5 \mathrm{hr}$. has been fixed for further study. The results obtained are shown in fig. 2.

3) Effect of Initial Concentration: It is found that by changing the concentration of metal ions from 20 to $40 \mathrm{mg} / \mathrm{L}$ the removal of metal ions from solution decreases. This is because of unavailability of adsorption sites. The results obtained are shown if fig. 3 .

4) Effect of Doses: It is observed that the removal of metal ions increases with the increase of doses of adsorbent. In this study the doses each of the treated tree bark and GAC varies from 0.5 to $3 \mathrm{~g}$. The results obtained are shown in fig. 4.

5) Effect of Temperature: It is observed that when each $1 \mathrm{gm}$ each of treated tree bark and GAC was agitated with $100 \mathrm{ml}$ metal ion solution for about 1.5 hour at different temperature the percent removal decreases 
with increases in temperature. The maximum removal of metal ions was observed at room temperature $\left(32^{\circ} \mathrm{C}\right)$. Hence, all further studies have been performed at $32^{\circ} \mathrm{C}$. The results are given in fig. 5 .

\section{B] Column Study:}

The optimum condition for adsorption of metal ion was obtained by using batch study. The results obtained in this study are used in column studies. In this study the collected wastewater samples were used. The optimum conditions of adsorption have been fixed in collected wastewaters. The wastewater samples having $51.3 \mathrm{mg} / \mathrm{L}$ of $\mathrm{Pb}(\mathrm{II})$ and its $\mathrm{pH}$ was fixed at 7.

The principle used for column studies is the solution containing metal ion is passed through two different column packed with treated tree bark \& GAC respectively in back flow mode. The metal ions present in solution is get preferentially adsorb on it. In the beginning the adsorption of metal is best and more as soon as time increases the adsorption capacity of column decreases due to blockage of adsorption site. The results obtained are mentioned in fig. 6 .

Fig. 1 Effect of pH on removal of $\mathrm{Pb}(\mathrm{II})$ using Treated tree bark \& GAC

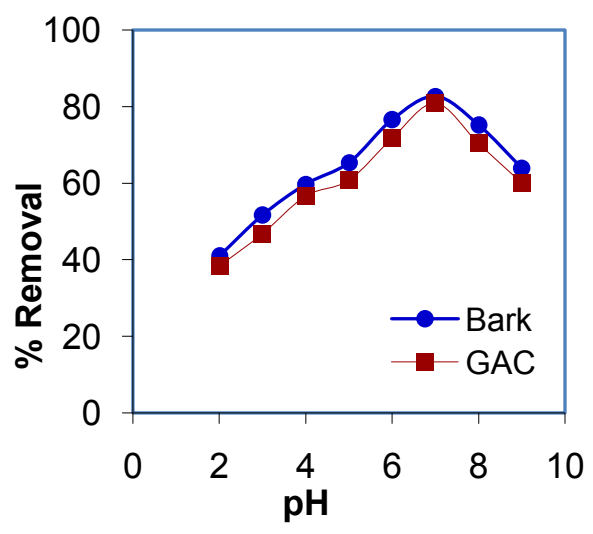

Fig. 2 Effect of Contact time on removal of $\mathrm{Pb}$ (II) using treated tree bark \& GAC

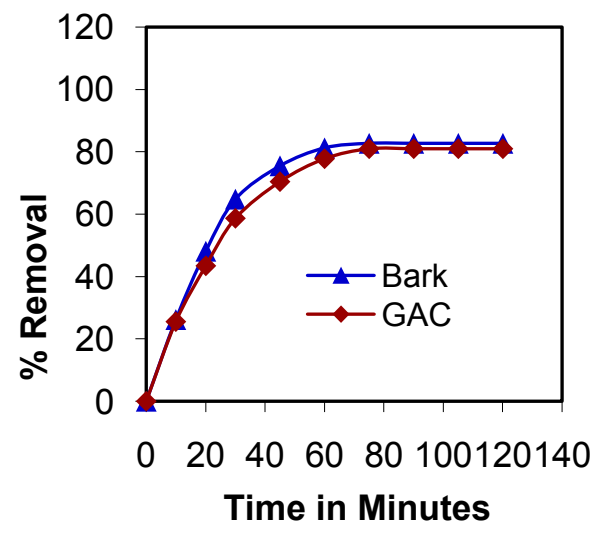


Fig. 3 Effect of Contact time on removal of $\mathrm{Pb}(\mathrm{II})$ using treated tree bark \& GAC

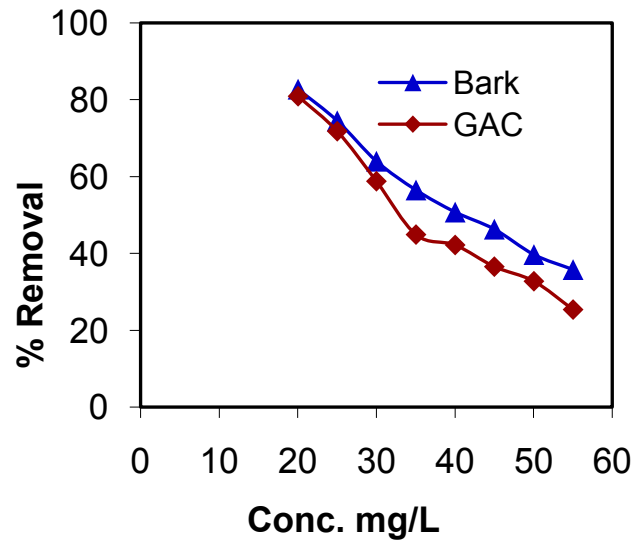

Fig. 4 Effect of Doses on removal of $\mathrm{Pb}(\mathrm{II})$ using treated tree bark \& GAC

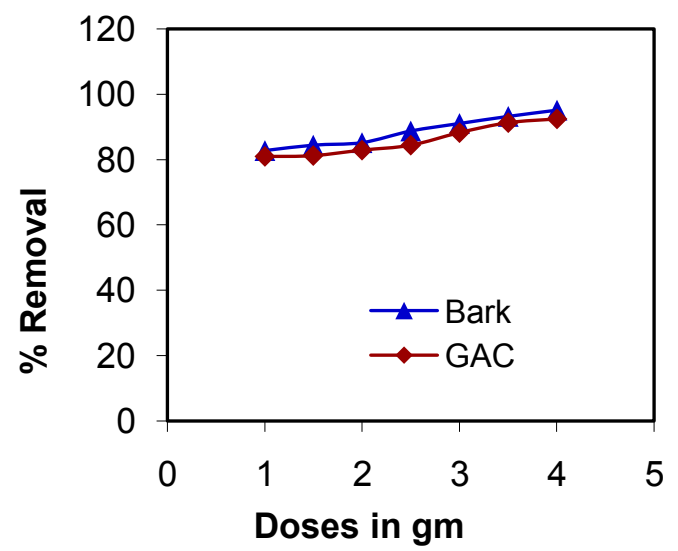

Fig. 5 Effect of Temperature on removal of $\mathrm{Pb}(\mathrm{II})$ using treated tree bark \& GAC

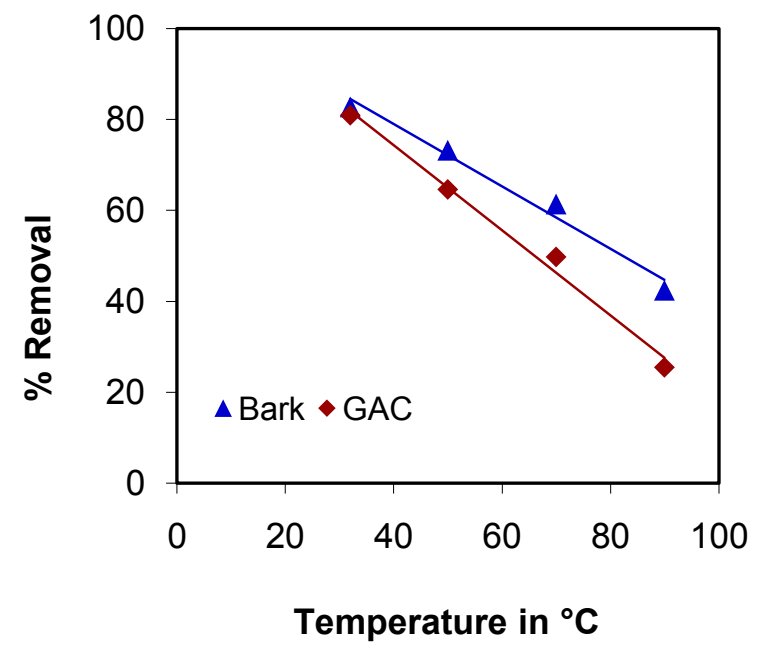


Fig. 6 Breakthrough curve for $\mathrm{Pb}$ (II) removal using treated tree bark \& GAC

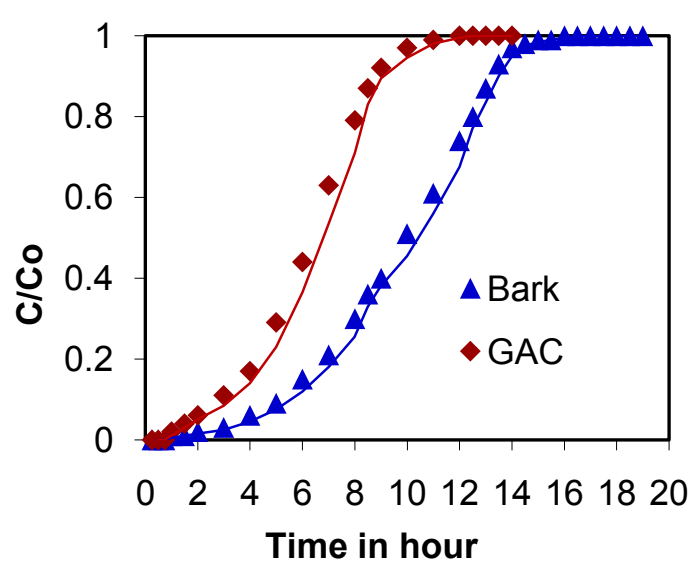

Fig. 7 First cycle desorption of $\mathrm{Pb}(\mathrm{II})$ using treated tree bark \& GAC

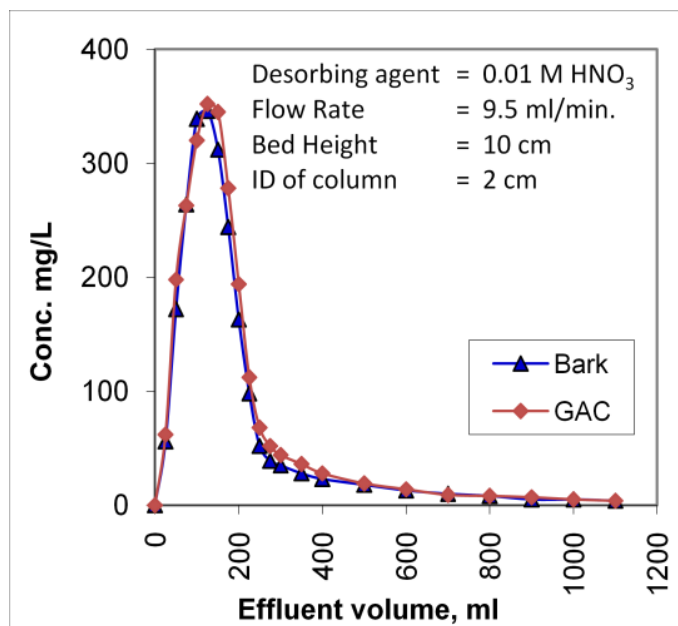

After the adsorption is over the regeneration of resin and GAC column is exhausted due to blockage of adsorption sites by metal ions. The regeneration of column is carried out by using $0.01 \mathrm{~N} \mathrm{HNO}_{3}$ solutions. The nitric acid solution was passed through the column at the same flow rate as that of the metal ion and effluent collected and analyzed for metal contents. It is observed that at beginning the metal concentration was too high and as the time increases the concentration of metal decreases.

\section{Conclusion:}

The present work is a sincere attempt for the removal of $\mathrm{Pb}$ (II) ions from industrial waste water using easily available and low cost natural polymeric substances the tree bark of Citrus limon. The results satisfactorily conclude that maximum absorption $\mathrm{Pb}$ (II) from solution on tree bark takes place at $\mathrm{pH}$ value between 6-7, The another most important finding is that its maximum adsorption takes place at room temperature and as doses of bark increases removal also increases. The maximum removal of metal ions occurs in time interval of 60-90 
minutes. The removal of metal ions decreases with increase of concentration of metal ion.

Hence, from all above results at mentioned conditions maximum removal of metal ions takes place using packed column treated Citrus limon tree bark. The comparable results obtained superior for bark rather than GAC. The advantages of bark are easy availability, cheapness, simple processing and effective removal of toxic metal ions without use of any sophisticated equipment and expert attention.

Based on the results obtained it is concluded that, the adsorbent tree bark seems to offer a less expensive but effective alternatives to the expensive commercial GAC. This adsorbent certainly can use in the tertiary treatment of industrial effluent. The results are encouraging and satisfactory.

\section{REFERENCES :}

Kenneth L. Dorris and Shyam S. Shukla, (2005) Removal of Cadmium from Aqueous Solution by Crab Shells. Res. J. of Chem. and Environ. 9(4): 42-45.

Iqbal, M. and A. Saeed, (2007) Production of an immobilized hybrid biosorbent for the sorption of $\mathrm{Ni}(\mathrm{II})$ from aqueous solution. Process Biochem., 42: 148-157.

Aydin, H., Y. Bulut and C. Yerlikaya, (2008) Removal of Cu(II) from aqueous solution by adsorption onto low-cost adsorbents. J. Environ. Manage., 87: 37-45.

Rao, M.M., D.H.K.K. Reddy, P. Venkateswarlu and K. Seshaiah, (2009) Removal of mercury from aqueous solutions using activated carbon prepared from agricultural by-product/waste. J. Environ. Manage., 90( 1): 634-643 [3] 
Qiu, Y., H. Cheng, C. Xu and S.D. Sheng, (2008) Surface characteristics of crop-residue-derived black carbon and lead(II) adsorption. Water Res., 42: 567-574.

Bhatti, H.N., B. Mumtaz, M.A. Hanif and R. Nadeem, (2007) Removal of zinc ions from aqueous solution using Moringa oleifera Lam. (horseradish tree) biomass. Process Biochem., 42: 547-553.

Malik, R., D.S. Ramteke and S.R. Wate, (2007) Adsorption of malachite green on groundnut shell waste based powdered activated carbon. Waste Manage., 27: 1129-1138.

Wan Nik, W.B., M.M. Rahman, A.M. Yusof, F.N. Ani and C.N. Che Adnan, (2006) Production of activated carbon from palm oil shell waste and its adsorption characteristics. In Proceedings of the $1 \mathrm{st}$ International Conference on Natural Resources Engineering and Technology 2006, pp: 646-654.

Upendra Kumar and Manas Bandyopadhyay, (2005) Fixed Bed Column Study for the Removal of Ni(II) from Aqueous Waste by NCRH. Res. J. of Chem. and Environ. 9(4): 81-86.

Pechyen, C., D. Atong, D. Aht-Ong and S. Viboon, (2007) Investigation of pyrolyzed chars from physic nut waste for the preparation of activated carbon. J. Solid Mechanics Material Eng., 1(4): 498-507.

Ramadevi A. and Srinivasan K. (2005) Agricultural Solid Waste for the Removal of Inorganics: Adsorption of Mercury (II) from Aqueous Solution by Tamarind Nut Carbon. Res. J. of Chem. and Environ. 9(1): 54-59. 